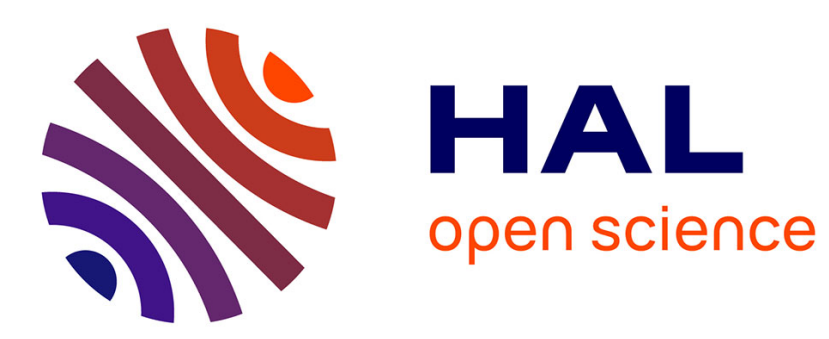

\title{
Quality-improving alliances in differentiated oligopoly
}

Frédéric Deroian, Frédéric Gannon

\section{To cite this version:}

Frédéric Deroian, Frédéric Gannon. Quality-improving alliances in differentiated oligopoly. International Journal of Industrial Organization, 2006, 24 (2), pp.629-637. 10.1016/j.ijindorg.2005.09.006 . halshs-00084891

\section{HAL Id: halshs-00084891 https://shs.hal.science/halshs-00084891}

Submitted on 10 Jul 2006

HAL is a multi-disciplinary open access archive for the deposit and dissemination of scientific research documents, whether they are published or not. The documents may come from teaching and research institutions in France or abroad, or from public or private research centers.
L'archive ouverte pluridisciplinaire HAL, est destinée au dépôt et à la diffusion de documents scientifiques de niveau recherche, publiés ou non, émanant des établissements d'enseignement et de recherche français ou étrangers, des laboratoires publics ou privés. 


\title{
Quality-improving alliances in differentiated oligopoly
}

\author{
Frédéric Deroian, EconomiX and G.R.E.Q.A.M. \\ and \\ Frédéric Gannon, EconomiX and University of Le Havre ${ }^{1}$,
}

\begin{abstract}
We study rival firms' incentives in quality-improving Research and Development $(R \& D)$ networks. The analysis stresses the role of free riding associated to collaboration and three major consequences emerge: R\&D efforts decrease with the number of partners, networks of alliances are over-connected as compared to the social optimum and the profitmaximizing number of alliances is possibly non monotonic (decreasing then increasing) with respect to inverse measure of product differentiation.
\end{abstract}

Keywords: Vertically and horizontally Differentiated Oligopoly, Product Innovation, R\&D Alliance

J.E.L. Classification: $C^{r} 70, L 13$, L20

\section{Introduction}

The incentives for rival firms to invest in Research and Development (R\&D) have been extensively studied in the literature. First, a long tradition, pioneered by Arrow (1962) and pursued by Spence (1984), sustains that knowledge creation cannot be fully appropriated, leading to involuntary knowledge leakages. Its main message is that incentives to invest in $R \& D$ are reduced by the presence of such spillovers. This raised the interest for R\&D cooperation as a means to internalize spillovers. Specifically focusing on cost-reducing R\&D, the literature initiated by d'Aspremont and Jacquemin (1988) compares cooperative and non cooperative schemes ${ }^{2}$ in oligopolistic industries in the presence of $\mathrm{R} \& \mathrm{D}$ spillovers. A major conclusion of that literature is that when spillovers are strong enough, cooperation entails

\footnotetext{
${ }^{1}$ EconomiX - Université Paris X - Bâtiment K - 200, avenue de la République - 92001 Nanterre, France. G.R.E.Q.A.M. - Vieille Charité - 2, rue de la Charité - 13002 Marseille, France. University of Le Havre Faculté des Affaires Internationales - 25, Rue Philippe Lebon - B.P 42076057 LE HAVRE Cedex.

E-mail addresses: fderoian@u-paris10.fr; frederic.gannon@wanadoo.fr.

2'Cooperative' [resp. 'non cooperative'] means that the individual R\&D levels maximize the joint profits [resp. individual profit] of all partners in the subsequent competing stage.
} 
more R\&D, output and welfare.

A recent theoretical trend examines more thoroughly the non cooperative incentives to form R\&D agreements: in Goyal and Moraga-González (2001), oligopolists can set up partnerships in order to share R\&D, before choosing non cooperatively an individual R\&D effort level. The authors show that increasing the number of partners generally leads to lower R\&D effort. Our paper follows the same approach. We depart from Goyal and MoragaGonzález (2001) by exploring quality-improving alliances. In the literature, few studies focus on quality-improving R\&D. Motta (1992) extends to product innovations the d'Aspremont and Jacquemin's cooperative framework, and confirms that cooperation leads to a higher R\&D level. Our conclusions differ from Motta (1992) in the non cooperative context, being clearly in line with Goyal and Moraga-González (2001).

The theoretical literature is supported by a number of empirical studies that document the emergence of contractual R\&D partnerships for the least three decades, distinct from research joint ventures. Hagedoorn (2002) finds that R\&D partnerships are sector-specific and stresses the importance of the biotech-pharmaceutical and Information Technology sectors (the latter including computers, telecom, semiconductors, industrial automation and software), both forming 80 percent of the newly made $R \& D$ alliances at the end of the 1990s. A second message is that the rationale for engaging in many $R \& D$ agreements is not only cost-cutting, but also strategic. R\&D agreements may not be related to the core activities of the firms but to other domains (Teece [1986]). Hence, R\&D partnerships are particularly useful for exploring high-risk areas of knowledge production, especially in turbulent environments. This flexibility often means horizontal diversification into new product lines (Link [1990], Vonortas [1997]), emphasizing the role of complementarities (and hence product differentiation) in order to access new resources (see Hagedoorn et al. [2000], and further references in their footnote 24 p. 579). That is, strategic flexibility is found to be a rationale for establishing contractual $R \& D$ alliances when competition is affected by increased technological development and the need to generate new products. In this context, product differentiation is an indicator of complementarities in the respective core competencies.

We relate in detail our results to Goyal and Moraga-González (2001) (GM thereafter). The authors propose a three-stage game in which firms first form collaborative links, then 
choose their levels of R\&D efforts, and finally compete in the product market.

GM first tackle the relationship between collaborative activity and individual R\&D levels. They show that in different (resp. homogenous) product markets, R\&D efforts are increasing (resp. decreasing) in the number of alliances. In our quality-improving setting, both different and homogenous product markets entail a decreasing relationship, due to the prominence of free riding. In strictly different markets, we find that the effort is independent from the number of partners.

The second result in GM pertains to the relationship between the level of collaboration and cost reduction. They find that when markets are different the cost reduction is maximal when the network is complete (i.e. the network in which all possible connections are formed), whereas in a single homogenous market the relationship is initially increasing and then decreasing. This stems from the following tradeoff: on the one hand increasing collaborative activity lowers the R\&D effort necessary to achieve a given marginal cost reduction, on the other hand the R\&D effort decreases with the number of alliances. Shifting the analysis from cost-reducing to quality-improving alliances, our results show that the relationship between the number of alliances and product quality is initially increasing and then decreasing (due to decreasing returns to collaboration).

Third, GM study firms' incentives to form alliances. In particular, the complete network is shown to be stable in both homogenous and different product markets. Further, focusing on regular networks (a regular network is such that all agents in the graph have the same number of partners), they find that in homogenous product markets firms' profits are maximized for an intermediate number of partners. Actually, as links add up a tradeoff emerges between savings in R\&D efforts and the cost-reducing effect of lower R\&D effort. This tradeoff also appears in our context for sufficiently low levels of product differentiation. Also, we provide an additional result: since GM only present two extreme market configurations, one could infer from their study that the larger the inverse measure of product differentiation, the smaller the number of alliances in stable networks. We address the issue. Considering all regular networks, it is possible to select the number of partners that maximizes individual profits, for a given level of horizontal product differentiation. Then, we demonstrate the possibility of a non monotonic relationship between this profit-maximizing number of partners and the inverse measure of product differentiation: while decreasing for relatively different markets, 
it may increase as we approach homogenous markets.

At last, GM suggest that competing firms may form too many alliances with respect to social welfare, and our findings are similar.

The paper is organized as follows. Section two describes the model. Section three studies firms' behavior and social welfare. Section four concludes.

\section{The model}

We adopt the three-stage game introduced by Goyal and Moraga-González (2001).

Graphs. The structure of alliances between the firms can be described as a non directed graph, in which nodes represent the firms and edges the R\&D alliances. A typical graph of alliances $g$ is thus a pair $(N, L)$ where $N$ is a set of firms and $L$ is a subset of all pairs of firms. We denote by $G$ the set of all non directed graphs with $N$ nodes. We shall abuse notation by writing that some link $i j \in g$ when firms $i$ and $j$ form an alliance in the graph $g$. We denote by $N_{i}(g)$ the set of firms with which firm $i$ forms a link in the graph $g$ and $k_{i}(g)$ represents the cardinal of $N_{i}(g)$ or firm i's degree (we shall replace $k_{i}(g)$ by $k_{i}$ when there is no confusion). Given a network $g$, we denote by $\pi_{i}(g)$ the profit made by firm $i$ on this network. A regular network of degree $k, k \in\{0, \ldots, n-1\}$, is such that all firms have $k$ partners, i.e. $k_{i}(g)=k$ for all $i \in N$. The complete network is such that $k_{i}(g)=n-1$ for all $i \in N$.

Industry. In the spirit of Sutton (1997), we consider a set $N=\{1, \cdots, n\}$ of firms, with $n \geq 2$, each producing a differentiated good. Each good $i$ is described by a quality index $u_{i}$ and by the quantity $x_{i} \geq 0$ sold to each consumer. There are $S$ identical consumers, each buying the entire variety of the $n$ brands. Their utility is represented by a quality augmented version of the standard quadratic utility function $U=\sum_{i \in N}\left(x_{i}-\frac{x_{i}^{2}}{u_{i}^{2}}\right)-\sigma \sum_{i} \sum_{j<i} \frac{x_{i}}{u_{i}} \frac{x_{j}}{u_{j}}+M$, where $M=Y-\sum_{i} p_{i} x_{i}$ denotes expenditures on outside goods, and the parameter $\sigma \in[0,2]$ is an inverse measure of the degree of horizontal product differentiation (from different products as $\sigma$ tends to 0 to homogenous products as $\sigma$ tends to 2). The derived individual inverse demand function for variety $i$ writes $p_{i}=1-\frac{2 x_{i}}{u_{i}^{2}}-\frac{\sigma}{u_{i}} \sum_{j \neq i} \frac{x_{j}}{u_{j}}$, in the region where prices and quantities are positive. 
$\mathbf{R} \& \mathbf{D}$ efforts and spillovers. Firms can invest in R\&D in order to increase quality. We denote by $e_{i}$ the effort made by firm $i$ and by $E=\left\{e_{1}, \cdots, e_{n}\right\}$ the effort profile in the industry. Firms can form alliances in order to share $R \& D$ efforts and benefit from the resulting increased quality level. For simplicity, we suppose that any firm's effort both exclusively and fully spills over her partners. Furthermore, there are no spillovers from outside the industry. Given a network $g$, knowledge sharing between firm $i$ and her partners aggregates in product $i$ 's quality in the following way: $u_{i}(E, g)=\epsilon\left[e_{i}+\sum_{j \in N_{i}(g)} e_{j}\right]^{\frac{1}{\gamma}}$, with $\gamma \geq 2$ and $\epsilon>0$. This formulation is a slight modification of Symeonidis (2003) and Motta (1992) and captures the public good nature of knowledge like Levin and Reiss (1988, equation (6) p. 541). A quality index should be interpreted as the perceived quality or attractiveness of the firm's product. It entails decreasing returns to $R \& D$ efforts produced by the partners. For instance, Levin and Reiss (1988) argue that "In a purely technological sense, the spillover of a rival's product $R \& D$ should enhance the quality of one's own product. But the output weights [...] reflect both tastes as well as technological attributes. Thus, the hedonic benefits derived from a product may decrease in response to a rival's product innovation." Furthermore, like in Goyal and Moraga-González (2001), the cost of producing individual effort $e_{i}$ is quadratic and given by $\alpha e_{i}^{2}, \alpha>0$. Given the effort profile $E$ and the network $g$, firm $i$ 's profit is denoted $\pi_{i}(E, g)$. Timing of moves. At stage 1, firms simultaneously form collaborative links, in order to share R\&D knowledge with partners. For the sake of simplicity, forming links is costless. At stage 2, the $R \& D$ alliances are set up and firms choose the individual level of $R \& D$ expenditure that maximizes their expected payoff. At stage 3, firms compete à la Cournot.

Stability. In principle, in a network formation game a stability criterion is posited. Here, however, the complexity of the strategic context leads us to follow the approach of Goyal and Moraga-González (2001) or Goyal et al. (2003), restricting analysis to regular networks. In the second stage, we focus on Nash-equilibria (concerning R\&D effort): a profile of efforts $\left\{e_{1}^{*}, \ldots, e_{n}^{*}\right\}$ is said to be a Nash equilibrium on the graph $g$ if $\pi_{i}\left(e_{i}^{*}, e_{-i}^{*}, g\right) \geq \pi_{i}\left(e_{i}, e_{-i}^{*}, g\right)$ for all $e_{i} \geq 0$ and for all $i \in N$; a symmetric Nash equilibrium on the graph $g$ is such that $e_{i}^{*}=e^{*}$ for all $i \in N$. We denote by $e^{*}(k)$ the symmetric Nash equilibrium individual effort on a regular network of degree $k$. The last stage is a standard Cournot competition, i.e. firm $i$ chooses the quantity $S \cdot x_{i}^{*}$ that maximizes her profit, given the quantities chosen by the other firms. 


\section{Results}

We first address the issue of firms' behavior, before studying social welfare.

Firms' behavior. We proceed by backward induction. At stage 3, firms choose a profitmaximizing quantity level, given a set of partners and a level of $R \& D$ effort. Standard optimization leads to the following equilibrium reduced-form payoff functions:

$$
\pi_{i}(E, g)=\frac{2 S}{(4-\sigma)^{2}(4+\sigma(n-1))^{2}}\left[(4+\sigma(n-2)) u_{i}(E, g)-\sigma \sum_{j \neq i} u_{j}(E, g)\right]^{2}-\alpha e_{i}^{2}, \forall i \in N .
$$

Let us emphasize a distinctive feature of this model with respect to vertical oligopoly models à la Shaked and Sutton (1982). Here, quality levels turn out to be strategic substitutes in the sense that a firm decreases its level of quality whenever competitive firms increase their qualities. This reinforces the tradeoff between R\&D collaboration and competition.

At stage 2, firms choose a profit-maximizing level of $\mathrm{R} \& \mathrm{D}$ effort, given the network of alliances. Replacing quality indexes by their expressions in terms of $R \& D$ efforts and partially differentiating function $\pi_{i}$ with respect to $e_{i}$, any candidate to (non constrained) maximization satisfies:

$$
\begin{gathered}
\frac{A}{\gamma}\left[(4+\sigma(n-2))\left(e_{i}+\sum_{k \in N_{i}(g)} e_{k}\right)^{\frac{1-\gamma}{\gamma}}-\sigma \sum_{k \in N_{i}(g)}\left(e_{k}+\sum_{l \in N_{k}(g)} e_{l}\right)^{\frac{1-\gamma}{\gamma}}\right] \times \\
{\left[(4+\sigma(n-2))\left(e_{i}+\sum_{k \in N_{i}(g)} e_{k}\right)^{\frac{1}{\gamma}}-\sigma \sum_{j \neq i}\left(e_{j}+\sum_{l \in N_{j}(g)} e_{l}\right)^{\frac{1}{\gamma}}\right]=\alpha e_{i},}
\end{gathered}
$$

with $A=\frac{2 S \epsilon^{2}}{(4-\sigma)^{2}(4+\sigma(n-1))^{2}}$ (note that the sum over all agents $k \neq i$ contains $k_{i}(g)$ times the element $e_{i}$, since $k_{i}(g)$ of them have agent $i$ as partner). Focusing on regular networks of degree $k$ and symmetric equilibria in $\mathrm{R} \& \mathrm{D}$ efforts, the interior solutions are written: $e^{*}(k)=$ $(k+1)^{\frac{2-\gamma}{2(\gamma-1)}}\left(\frac{A(4-\sigma)(4+\sigma(n-2-k))}{\alpha \gamma}\right)^{\frac{\gamma}{2(\gamma-1)}}$, entailing the equilibrium quantity $S \frac{\left[(k+1) e^{*}(k)\right]^{\frac{2}{\gamma}}}{4+\sigma(n-1)}$, the equilibrium price $\frac{2}{4+\sigma(n-1)}$ and the equilibrium profit $\pi^{*}(k)=A(4-\sigma)^{2}\left[(k+1) e^{*}(k)\right]^{\frac{2}{\gamma}}-$ $\alpha e^{*}(k)^{2}$.

We denote $\gamma^{p}=\frac{4+\sigma(n-2-k)}{(4-\sigma)(k+1)}$. The following claim imposes a necessary and sufficient 
condition on the parameter $\gamma$ for a regular network of degree $k$ to support both positivity and concavity of profit functions.

Claim 3.1 Consider a regular network of degree $k$ and suppose that $\gamma>\gamma^{p}$. Then profits are positive and concave with respect to the effort level on this regular network.

Proof. At equilibrium positivity implies concavity if $\gamma \geq 2$ : first, profits are positive iff $k>k^{p}$ with $k^{p}=\frac{4+\sigma(n-2)-\gamma(4-\sigma)}{\gamma(4-\sigma)+\sigma}$. Second, let us consider profit concavity in $e_{i}$ : differentiating twice the profit function with respect to $e_{i}$, then focusing on the symmetric case, we obtain after rearrangement the condition $k>k^{c}$ with $k^{c}=\frac{4+\sigma(n-2)-(2 \gamma-1)(4-\sigma)}{\gamma(4-\sigma)+\sigma}$. Finally $k^{c}<k^{p}$ iff $\gamma>1$. Moreover, the positivity condition can be written $\gamma>\gamma^{p}$.

In what follows, we assume $\gamma>\frac{4+\sigma(n-2)}{(4-\sigma)}$, so that both positivity and concavity of profits prevail on any regular network. For lower values of $\gamma$, the conditions only hold on regular networks with sufficiently high degree; otherwise firms do not collaborate with each other. The following proposition shows that the equilibrium R\&D efforts on regular networks decrease with the number of partners.

Proposition 3.1 Consider a regular network of degree $k$. Then, individual R\&D efforts decrease with the number of partners.

Proof. Approximating $e(k+1)-e(k)$ by partial derivative, the condition is written:

$$
\frac{\partial e(k)}{\partial k} \sim(k+1)^{\frac{4-3 \gamma}{2 \gamma-2}}(4+\sigma(n-2-k))^{\frac{2-\gamma}{2 \gamma-2}}((2-\gamma)(4+\sigma(n-2))-\gamma \sigma-2 \sigma k) .
$$

The derivative is negative for $\gamma>2 \frac{4+\sigma(n-2-k)}{+\sigma(n-1)}$, with RHS less than 2 .

This result is in line with Goyal and Moraga-González (2001) and stems from the fact that high individual R\&D efforts strongly benefit partners.

The profit-maximizing quality is $u^{*}(k)=\left[(k+1) e^{*}(k)\right]^{\frac{1}{\gamma}}$. Therefore, given the decreasing returns to cooperation, the following proposition obtains.

Proposition 3.2 Consider a regular network of degree $k$. The symmetric equilibrium level of quality $u^{*}(k)$ is a non monotonic function of the degree $k$. It increases until $k^{u}=\frac{4+\sigma(n-3)}{2 \sigma}$ and then decreases. 
Proof. $u^{*}(k)$ is proportional to $[(k+1)(4+\sigma(n-2-k))]^{\frac{1}{2 \gamma-2}}$. The result follows directly, noting that $k^{u}>k^{p}$ iff $\gamma>\frac{\sigma}{4-\sigma}$, which is valid for all $\gamma \geq 2$ and all $\sigma \in[0,2]$.

In other words, when firms ally with few partners the collaborative activity generates high returns, so that the addition of one link per firm increases quality even if the individual effort is decreasing. By contrast, when the number of partners is large, the return from one additional link does not compensate for the decrease in individual effort.

We determine the (symmetric equilibrium) profit levels attained on each regular network. Let us define by $k^{*}$ the profit-maximizing degree, i.e. the degree for which the largest individual profits obtain.

Proposition 3.3 When markets are different $(\sigma=0)$, the complete network maximizes firms' profits $\left(k^{*}=n-1\right)$. When markets are homogenous $(\sigma=2)$, the profit-maximizing degree is equal to $\frac{(2+\sqrt{2 \gamma(\gamma-1)}) n+\sqrt{2 \gamma(\gamma-1)}-2 \gamma}{2(1+\gamma)}$, which is less than $n-1$.

Proof. Replacing $e^{*}(k)$ by its expression in the equilibrium profit, we find

$$
\pi^{*}(k)=E \cdot\left[(k+1)(4+\sigma(n-2-k)]^{\frac{1}{\gamma-1}}-F \cdot(k+1)^{\frac{2-\gamma}{\gamma-1}}(4+\sigma(n-2-k))^{\frac{\gamma}{\gamma-1}},\right.
$$

with $E$ and $F$ two constants such that $\frac{E}{F}=(4-\sigma) \gamma$. Then $\frac{\partial \pi^{*}(k)}{\partial k}<0$ iff:

$$
(4-\sigma) \gamma(4+\sigma(n-3)-2 \sigma k)(k+1)<(4+\sigma(n-2-k))((2-\gamma)(4+\sigma(n-2))-\sigma \gamma-2 \sigma k) .
$$

When markets are different $(\sigma=0)$, the condition becomes $k<2 \frac{1-\gamma}{\gamma}$, which is impossible; then $k^{*}=n-1$. When markets are homogenous $(\sigma=2)$, we obtain $\frac{\partial \pi^{*}(k)}{\partial k}<0$ iff $2(1+$ $\gamma) k^{2}+4(\gamma-n) k+(2-\gamma) n^{2}-2 \gamma n+\gamma>0$; computations indicate that the first root is negative for all $\gamma \geq 2$ and the second root is given by $k^{*}=\frac{(2+\sqrt{2 \gamma(\gamma-1)} n+\sqrt{2 \gamma(\gamma-1)}-2 \gamma}{2(1+\gamma)}$.

When $\sigma \in] 0,2[$, it can be shown that positive equilibrium profits are increasing and then possibly decreasing in $k$ for $\gamma \geq 2$. In what follows we set $\gamma=2$. This is because for this 
specific value closed-form solutions obtain; otherwise the analysis is cumbersome ${ }^{3}$. First note that, given the above claim, low values of $k$ may not be compatible with positive profit. Second we have $e^{*}(k)=\frac{A}{2 \alpha}(4-\sigma)(4+\sigma(n-2-k))$. Denoting $K=\frac{A^{2}(4-\sigma)^{2}}{4 \alpha}$, and rearranging the profit function, we obtain a profit quadratic in $k: \pi^{*}(k)=K(4+\sigma(n-2-k))[(8-\sigma) k+4-\sigma n]$, for all $k$ such that profit is positive. From this equation we derive the profit-maximizing value of collaborative activity and we express it as a function of product differentiation: $k^{*}(\sigma)=\frac{\sigma^{2}+4(n-3) \sigma+16}{\sigma(8-\sigma)}$. The value of $\sigma$ that minimizes $k^{*}$ is $\tilde{\sigma}=4 \frac{\sqrt{2 n-1}-1}{n-1}$, which is less than 2 for $n>5$. Further, we easily obtain $k^{*}(\tilde{\sigma}(n))=\frac{4 n-1+\sqrt{2 n-1}\left(n^{2}-4 n+1\right)}{2(n \sqrt{2 n-1}-2 n+1)}$, which tends to $\frac{n}{2}$ when $n$ tends to infinity. The results are summarized in the following proposition.

Proposition 3.4 When $\gamma=2$, the profit-maximizing degree is $n-1$ for different markets $(\sigma=0)$ and is $\frac{2 n-1}{3}$ for homogenous markets $(\sigma=2)$. Furthermore, in large industries the relationship between the profit-maximizing degree and the inverse measure of product differentiation is non monotonic.

Proof. The proof will be complete when checking positivity and second order constraints. As stated in the above claim, the second order condition is guaranteed by the positivity condition. We note that $k^{p}$ increases with $\sigma$ and $k_{\mid \sigma=2}^{p}=\frac{n-2}{3}$. This value is less than the profit-maximizing value $k^{*}(\sigma)$. Hence, when $k \leq k^{p}$, profit is negative for any positive effort, which is inconsistent with firms' maximizing behavior. Then firms do not form alliances and get equilibrium profit equal to $\frac{A^{2}(4-\sigma)^{2}(4+\sigma(n-2))(4-\sigma n)}{4 \alpha}$ (with $A$ defined as above). But this value is smaller than $\pi^{*}\left(k^{*}(\sigma)\right)=\frac{A^{2}(4-\sigma)^{2}\left(-\sigma^{2}(n-1)+4(n-2) \sigma+16\right)^{2}}{4 \alpha \sigma(8-\sigma)}$ for all $\sigma \in[0,2]$.

The proposition has different implications for small versus large oligopolies. For relatively small oligopolies $(n \leq 5), k^{*}(\sigma)$ is decreasing whereas for $n \geq 6$ the relationship is decreasing

\footnotetext{
${ }^{3}$ Indeed, from the above inequality we obtain that $\frac{\partial \pi^{*}(k)}{\partial k}<0$ iff $C_{1} k^{2}+C_{2} k+C_{3}>0$, with

$$
\left\{\begin{array}{l}
C_{1}=2 \sigma(\sigma+(4-\sigma) \gamma) \\
C_{2}=-4 \sigma(4+\sigma(n-2))-2 \gamma\left(-\sigma^{2}(n-3)+2(n-7) \sigma+8\right) \\
C_{3}=2(4+\sigma(n-2))^{2}-\gamma\left[32+4 \sigma(3 n-7)+\sigma^{2}\left(n^{2}-4 n+5\right)\right]
\end{array}\right.
$$

with $C_{3}<0$ iff $\gamma>\frac{2(4+\sigma(n-2))^{2}}{32+4 \sigma(3 n-7)+\sigma^{2}\left(n^{2}-4 n+5\right)}$. When $\sigma=2$, this means $\gamma>\frac{2 n^{2}}{n^{2}+2 n-1}$, the RHS of which is less than 2. Further, defining $f(\sigma)=\frac{(4+\sigma(n-2))^{2}}{32+4 \sigma(3 n-7)+\sigma^{2}\left(n^{2}-4 n+5\right)}, f^{\prime}(\sigma) \sim(n-1)\left[\sigma^{2}(n-2)(n-4)+8 \sigma(n-3)+16\right]$, which is positive. Hence we are sure that for any $\gamma>2, C_{3}<0$. Thus there are two roots, the smallest of which being negative: profits increase and eventually decrease if the largest root is less than $n-1$.
} 
and then increasing. Indeed, the strength of the free riding effect increases with the size of the industry, in the sense that when goods are relatively homogenous, firms are led to form more alliances in order to alleviate the cost of their individual $R \& D$ effort.

Consumer surplus and total welfare. We find a general tendency to over-connection and under-investment in $R \& D$ with respect to social welfare (defined as the sum of aggregate profits and consumer surplus). Indeed, in such a competitive environment, spillovers lower individual incentives to exert effort, and firms behave partly as free riders, using links as a means to decrease the effort necessary to produce quality.

The relationship between consumer surplus (denoted $C S$ ) and the number of collaborative links is non monotonic, reaching its maximum value $k^{c s}$ for intermediate values of $k$. Indeed, $C S=S \cdot V$ with $V=U-\sum p_{i} x_{i}$, which writes as $V=n \frac{2+\sigma(n-1)}{2}\left(\frac{x^{*}}{u^{*}}\right)^{2}$ at equilibrium. Given that $\frac{x^{*}}{u^{*}}=\frac{u^{*}}{4+\sigma(n-1)}$, consumer surplus at equilibrium is proportional to the square of quality index, and $k^{c s}=k^{u}=\frac{4+\sigma(n-3)}{2 \sigma}$ (which is independent from $\gamma$ ). The comparison with the profit-maximizing degree reveals a general over-connection problem.

Proposition 3.5 For all $\sigma \in[0,2]$, the profit-maximizing degree is greater than both the consumer surplus-maximizing degree and the welfare-maximizing degree.

Proof. As $\gamma=2$, consumer surplus is quadratic (concave) in $k$. Hence, the profit-maximizing degree is greater than the consumer surplus-maximizing degree if the condition $\frac{\partial \pi\left(k^{c s}\right)}{\partial k}>0$ holds. Therefore, using footnote 3 and replacing both $k^{c s}$ by its expression $\frac{4+\sigma(n-3)}{2 \sigma}$ and parameters $C_{1}, C 2, C_{3}$ by their respective values, we find after development that $\frac{\partial \pi\left(k^{c s}\right)}{\partial k}>0$ iff $1<\gamma$. As a consequence, the social welfare-maximizing degree is by definition less than the profit-maximizing degree.

\section{Concluding remarks}

We have studied quality-improving $\mathrm{R} \& \mathrm{D}$ alliances in an oligopolistic context. We have shown that R\&D efforts decrease with the number of partners, networks of alliances are over-connected as compared to the social optimum and the profit-maximizing number of alliances is non monotonic (decreasing and then increasing) with respect to the inverse measure 
of product differentiation for large industries.

There are several directions in which the model could be extended. First, the analysis is restricted to regular networks, which limits the generality of the results. Second, comparing Bertrand and Cournot equilibria could be a useful follow-up to the present analysis, both in terms of profit-maximizing behavior and welfare analysis (see Symeonidis [2003] in duopolistic competition). Third, our results are sensitive to our specification of the relationship between R\&D expenditures and quality indexes. Further, spillovers might disseminate to non-partner firms, or come from outside the industry. Fourth, the usual dichotomy between process and product innovation could be qualified for at least two reasons. Complementarities exist in the sense that product innovation often requires a decrease in marginal costs to be effective. Moreover, firms may have to choose between process and product innovation (Bonanno and Haworth [1998]). Finally, the empirical literature suggests that product differentiation is a decisive factor in partner choice, which pleads for making this parameter endogenous.

\section{ACKNOWLEDGEMENTS}

We are grateful to the editor, Professor Oz Shy, and two anonymous referees for their comments and suggestions, which greatly contributed to improve the quality of the article. We are also indebted to Frank Eich and Nicolas Jonard for comments on early drafts, as well as participants in the seminar "Economies d'Interactions, Réseaux et Coalitions", G.R.E.Q.A.M., Marseille.

\section{REFERENCES}

Bonanno, G. and B. Haworth, 1998, Intensity of competition and the choice between product and process innovation, International Journal of Industrial Organization, 16, 495510.

d'Aspremont, C. and A. Jacquemin, 1988, Cooperative and noncooperative R\&D in duopoly with spillovers, American Economic Review, 78, 1133-1137.

Goyal, S. and J. L. Moraga-González, 2001, R\&D networks, Rand Journal of Economics, 32, 686-707.

Goyal, S., A. Konovalov and J. L. Moraga-González, 2003, Hybrid R\&D, Tinbergen Institute discussion paper TI 2003-041/1. 
Hagedoorn, J., 2002, Inter-firm R\&D partnerships: an overview of major trends and patterns since 1960, Research Policy, 31, 477-492.

Hagedoorn, J. and H. van Kranenburg, 2003, Growth patterns in R\&D partnerships: an exploratory statistical study, International Journal of Industrial Organization, 21, 517-531.

Hagedoorn, J., A. Link and N. Vonortas, 2000, Research partnerships, Research Policy, 29, $567-586$.

Levin, R. and P. Reiss, 1988, Cost-reducing and demand creating R\&D with spillovers, RAND Journal of Economics, 19, 538-556.

Link, A., 1990, Strategies for cooperation in R\&D, In: Khalil, T., Bayraktar, B. (Eds.), Management of Technology, Institute of Industrial Engeneering, Miami, 335-343.

Motta, M., 1992, Co-operative R\&D and vertical product differentiation, International Journal of Industrial Organization, 10, 643-661.

Shaked, A. and J. Sutton, 1982, Relaxing price competition through product differentiation, Review of Economic Studies, 49, 3-13.

Sutton, J., 1997, One smart agent, Rand Journal of Economics, 28, 605-628.

Symeonidis, G., 2003, Comparing Cournot and Bertrand equilibria in a differentiated duopoly with product R\&D, International Journal of Industrial Organization, 21, 39-55.

Teece, D., 1986, Profiting from technological innovation: implications for integration, collaboration, licensing and public policy, Research Policy, 15, 285-305.

Vonortas, N., 1997, Cooperation in Research and Development, Kluwer Academic Publishers, Boston. 